\title{
Constructing Aggregate Environmental-Economic Indicators: A Comparison of 12 OECD Countries
}

\author{
J.C.J.M. van den Bergh en D.B. van Veen-Groot ${ }^{1}$ \\ Department of Spatial Economics \\ Free University \\ De Boelelaan 1105 \\ $1081 \mathrm{HV}$, Amsterdam, the Netherlands \\ Email: jbergh@econ.vu.nl and dveen@econ.vu.nl.
}

\footnotetext{
${ }^{1}$ We are grateful to Cees van Beers for comments on an earlier version, and to Hadewijch van Delft for assistance with the translation of the original Dutch text into English.
} 


\begin{abstract}
The application of aggregate indicators in environmental-economic research has received little attention so far. An important reason is the incompleteness of environmental data. This article presents a systematic approach to construct indicators of environment and economy on a macro level. It includes a distinction into the following categories: the volume of economic activities as an indicator of potential environmental pressure; actual environmental pressure; environmental quality; and environmental policy. In each category aggregate indicators are calculated for 12 OECD countries. Subsequently, the correlation between these indicators is examined. Significant correlation is found between the economic activity indicators (or 'potential' environmental pressure), actual environmental pressure and environmental quality, whereas a very weak correlation exists with these indicators and two types of aggregate indicators of environmental policy. Due to some arbitrary choices, which are inevitable, the results are to be judged with caution. Several suggestions are offered to improve the calculation and comparison of aggregate indicators.
\end{abstract}




\section{Introduction}

The choice and calculation of aggregate indicators of environmental pressure and environmental quality has received quite a lot of attention from natural and environmental scientists. The present article will extend and relate these to aggregate indicators of economic activity as potential environmental pressure, and to aggregate indicators of strictness of environmental regulations. Together, these four indicators can improve our understanding of economy-environment interactions and changes in these. Moreover, such a system of indicators allows for comparisons among countries. In particular, these indicators are very useful in ex-post evaluation of environmental policy. Especially economists can make use of the latter type of indicators, for instance, in studies of the impacts of differences in environmental regulations among countries on international trade flows and plant location decisions by multinationals (see van Beers and van den Bergh, 1997).

Various attempts have been made to aggregate environmental data. Den Butter (1992) and den Butter and van de Eyden (1998) focus on the environmental quality of The Netherlands. Hope et al. (1992) develop an environmental quality index for Great Britain. De Bruyn and Opschoor (1997), following Jänicke et al. (1989), offer a discussion on aggregate environmental pressure indicators. Van der Laan and Nentjes (1992) aggregate environmental data to compare environmental pressure in The Netherlands with that in other European countries. The literature on activity and policy indicators is less rich. Van Beers and van den Bergh (1997) have attempted to quantify environmental policy through various indicators. Goff (1996) offers some methodological considerations for formulating aggregate indicators of policy. Other, more general discussions of indicators are Kuik and Verbruggen (1991), Adriaanse (1993), and Milon and Shogren (1995).

An important problem in the composition of indicators is the difficulty or impossibility of translating environmental problems into single units (van den Bergh and Verbruggen 1999). Scientists and policy makers have discussed how then to weigh different problems or partial indicators to arrive at aggregate indicators. In the calculations presented later components of aggregate indicators will be equally weighed. 
The reason for this is that no agreement exists on how to determine the weights. Huppes et al. (1997) describe the following methods for determining the weights: political statements, "revealed preferences", government objectives, individual preferences and sustainability criteria. Moreover, the discussion about weights has focused on environmental pressure and quality indicators. Weighing in aggregation of data for constructing economic activity (potential environmental pressure) and policy indicators is a completely different matter.

A second problem concerns the quality of environmental data. For some years now, both for the Netherlands and the OECD, environmental data have been collected on a regular basis. However, the data is not complete. Although a great number of indicators are imaginable ${ }^{2}$, the choice of indicators in this study is influenced by limited availability of data for the selected OECD-countries. This is the case even after the countries were selected on the condition that a minimal amount of environmental data was available.

Another issue that deserves attention in composing aggregate environmental indicators is choice between units per capita (inhabitant) or per area. We have decided to relate the indicators to area. An important reason is that economic activities and the resulting environmental pressure and quality mainly have relations with local environmental problems. For global environmental problems caused by emissions of CFI's and $\mathrm{CO}_{2}$ it would perhaps be preferable to use an indicator per country normalised for the number of inhabitants.

The organization of this article is as follows. In Section 2 a framework is presented for the selection of the four types of aggregate indicators. These will be elaborated and quantified in Sections 3 to 6. Next, Section 7 examines whether an empirical relation exists between the aggregate environmental, environmental policy and a number of macro-economic indicators. Finally, Section 8 presents the main conclusions.

\footnotetext{
${ }^{2}$ See for an overview: http://www.un.org/dpcsd/dsd/isd.htm
} 


\section{A framework for environmental and economic indicators}

The general framework is presented in Figure 1. It shows a causality chain that guides the classification of environmental data by the OECD (1995) and the RIVM (1995). This classification offers clues for selecting sub-indicators that can serve as input for aggregate indicators of economic activities (potential environmental pressure), actual environmental pressure, environmental quality and environmental policy. ${ }^{3}$ A logical starting point is the system of consumption and production that leads to emissions of polluted materials to air, water and soil, and disturbance of nature and the environment (odour, noise, and isolation of nature areas due to physical infrastructure). Indicators of these factors can provide information about the potential environmental pressure (arrow 1 in Figure 1). Environmental pressure caused by specific sectors can be reduced by investments in cleaner technologies. It is thus possible that whereas economic activity levels increase, environmental pressure decreases (also arrow 1). This process has been referred to as 'delinking'.

A reduction in environmental pressure does not necessarily result in an improvement in environmental quality. Emissions abroad may lead to a disproportionate relation between domestic environmental pressure and environmental quality. Moreover, cumulative, threshold and delayed impacts, as well as low removal speeds of some materials, can cause environmental quality to respond in a non-linear way to changes in environmental pressure (arrow 2 in Figure 1). The nature and size of economic activities and the environmental pressure and quality can be influenced by government policy, which includes environmental policy, economic policy, physical planning and technology policy (arrow 3 in Figure 1). This study will focus on indicators of environmental policy in a strict sense.

\footnotetext{
${ }^{3}$ This framework exhibits many similarities with the framework of the European Environmental Agency (Stanners and Bourdeau, 1995) in which a distinction is made between 'human activities', 'pressures', 'environmental conditions' and 'environmental problems': policy measures can affect all these areas.
} 


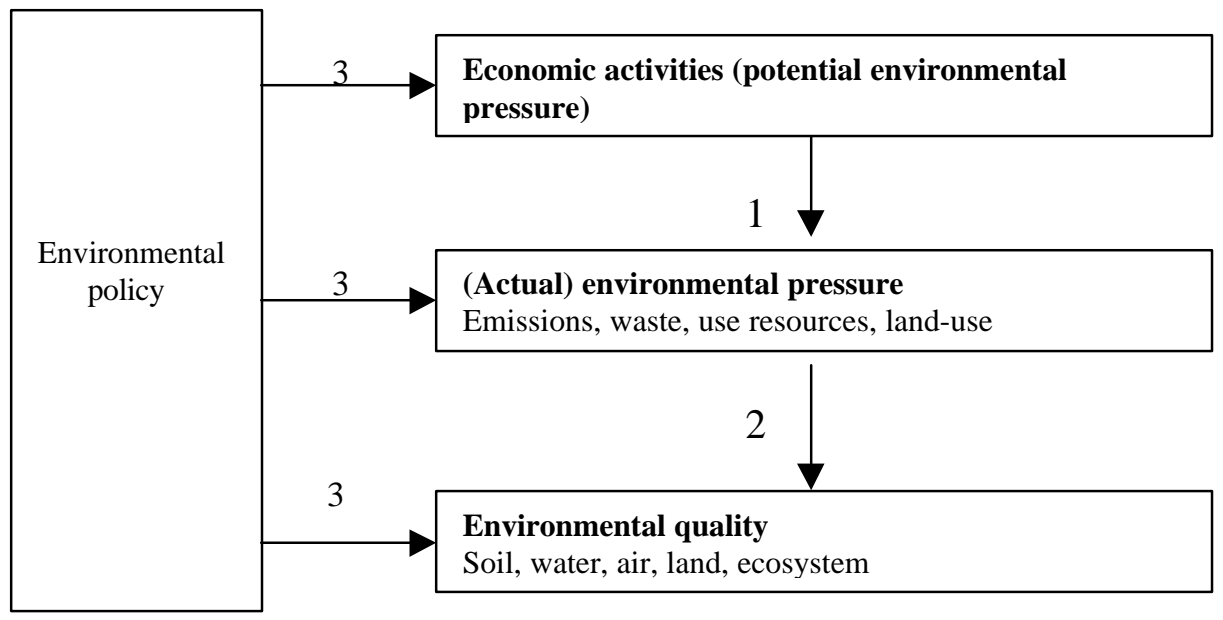

Figure 1. Relationship between economy-environment causality chain and policy. Based on RIVM (1995) and OECD (1995).

Four types of aggregate indicators will be identified hereafter: for economic activities, environmental pressure, environmental quality and environmental policy. These will be calculated for a number of OECD-countries, and be compared. In addition, we will investigate the existence of a relation between the calculated indicators. The analysis will cover 12 OECD-countries that are comparable in various respects, and for which sufficiently similar data are available, namely: Canada, United States, Japan, Austria, Finland, France, Germany, the Netherlands, Portugal, Spain, Sweden and Switzerland. The sub-indicators and indicators are normalised on a continuous scale from 0.00 to 1.00 . A higher value does not generally imply 'better' (or 'worse') but follows a certain logic within each of the four categories of indicators (whenever confusion is possible tables with results will include an explanation). Since for some sectors or environmental problems more indicators are available than for others, these would have a disproportionally large influence on the aggregate indicator. This bias is avoided by weighed summation, such that each sector or environmental 
problem has an equal weight in the aggregate indicator. ${ }^{4}$ However, as discussed in the introduction, no weighing will be applied that reflects the relative seriousness of environmental problems or sub-indicators.

\section{Indicators of economic activities as potential environmental pressure}

The size of economic activities can be regarded to give a first indication of potential environmental pressure $\left(I_{e}\right)$. Table 1 presents possible indicators of the influence of economic activities on environmental pressure. A distinction into polluting sectors in the economy is made, namely the energy sector, transport, industry and agriculture.

Table 1. Indicators of the influence of economic activities on environmental pressure (potential environmental pressure).

\begin{tabular}{ll}
\hline Sector & Subindicators \\
\hline Energy & a. Energy use (Mtoe) ${ }^{*}$ per inhabitant (1993) \\
& b. \% fossil fuels (oil, coal, gasses: in Mtoe) (1993) \\
& c. \% alternative energy sources (hydro/geothermal/solar energy) (1993) \\
\hline Transport & d. Number of cars per $\mathrm{km}^{2}(1993)$ \\
& e. Number of kilometres per $\mathrm{km}^{2}$ (1993) \\
& f. Km road per km ${ }^{2} \quad(1993)$ \\
\hline Industry & g. \% industry of GNP (1993) \\
\hline horticulture / & h. Use of fertiliser per $\mathrm{km}^{2}$ (1993) \\
& i. Use of pesticides per $\mathrm{km}^{2}$ (last year available) \\
j. Number of pigs per $\mathrm{km}^{2}$ (1993) \\
k. Number of cows per $\mathrm{km}^{2}$ (1993)
\end{tabular}

Note: $*$ Mtoe $=$ million tonnes oil equivalent.

A short explanation of the chosen indicators follows. The use of energy leads to exhaustion of non-renewable resources and air pollution. The latter concerns local air pollution, caused by traffic, and 'international or global air pollution', causing global warming

\footnotetext{
${ }^{4}$ The data are based on OECD (1985b, 1993, 1994, 1995).
} 
and acidification. The energy use per inhabitant (in Table 1 presented by (a)) is high in rich countries like Canada, the United States and Finland. South-European countries like Portugal and Spain have a low energy use. Furthermore, the use of fossil fuels (b) is an important indicator of potential environmental pressure. Switzerland, Sweden and France make relatively little use of fossil fuels, whereas Portugal, the Netherlands and the United States have high levels of fossil fuel use. Less environmentally damaging energy sources, such as wind and solar (photovoltaic cell) energy, hydro and geothermal energy (c), are used intensively in Canada, the United States and Japan. ${ }^{5}$ Finland and Portugal make relatively little use of alternative energy sources.

The most important components of environmental pollution by traffic are air pollution (emissions of $\mathrm{CO}_{2}, \mathrm{SO}_{2}, \mathrm{NO}_{\mathrm{x}}$, VOS and lead) and noise pollution. Other problems are "land division" (resulting from infrastructure), congestion and accidents. Possible indicators of traffic refer to car ownership and car use. However, environmental pressure becomes only really clear when traffic movements are related to the size of the area in which the movements take place. Consequently, in countries where the population density, car-ownership and mobility are high, the environmental pressure associated with transport is high. This becomes evident when we look at indices for different indicators of transport. In Canada and Sweden the number of cars and the kilometres driven per area-unit are low. Obviously, in countries with a high population density like The Netherlands or Japan these indicators obtain a high value.

Next, the level of industrial activity seriously influences the amount of produced waste, emissions to water and air, etc. The sector structure of production in a country tells something about the pressure that industrial activities have on the environment. The OECD distinguishes three main sectors: industry, agriculture and services. The size of the industry sector is presented as a percentage of GNP. Countries with a small percentage are assumed to be relatively clean are the United States, Canada and Sweden (environmental impacts of agriculture are registered separately via the indicators $h$ to $k$ ). Relatively dirty are countries like Japan, Germany and Portugal.

\footnotetext{
${ }^{5}$ A low value of this indicator expresses an intensive use of alternative energy sources and, therefore, a low
} 
Table 2. Aggregation of indicators of potential environmental pressure in OECD countries.

\begin{tabular}{|l|ccc|ccc|c|cccc|c|}
\hline & \multicolumn{3}{|c|}{ Energy } & \multicolumn{3}{|c|}{ Transport } & Industry & \multicolumn{3}{|c|}{ Agriculture } & \\
\hline & $\mathrm{A}$ & $\mathrm{B}$ & $\mathrm{c} \mathrm{c}^{* *}$ & $\mathrm{~d}$ & $\mathrm{E}$ & $\mathrm{f}$ & $\mathrm{g}$ & $\mathrm{h}$ & $\mathrm{i}$ & $\mathrm{j}$ & $\mathrm{k}$ & $\mathrm{I}_{\mathrm{e}}^{* * *}$ \\
\hline Cn* & 1,00 & 0.79 & 0,00 & 0.01 & 0,01 & 0.03 & 0.64 & 0,02 & 0,03 & 0,00 & 0,02 & 0.39 \\
$\mathrm{US}$ & 0,93 & 0.92 & 0,00 & 0.10 & 0,14 & 0.20 & 0.66 & 0,15 & 0,20 & 0,00 & 0,15 & 0.48 \\
$\mathrm{Jp}$ & 0,43 & 0.86 & 0,01 & 0.70 & 0,71 & 0.93 & 1.00 & 0,34 & 0,93 & 0,08 & 0,34 & 0.82 \\
$\mathrm{Au}$ & 0,48 & 0.91 & 0,03 & 0.26 & 0,27 & 0.41 & 0.85 & 0,22 & 0,41 & 0,41 & 0,22 & 0.60 \\
$\mathrm{Fi}$ & 0,78 & 0.78 & 1,00 & 0.04 & 0,05 & 0.07 & 0.67 & 0,07 & 0,07 & 0,11 & 0,07 & 0.51 \\
$\mathrm{Fr}$ & 0,45 & 0.61 & 0,08 & 0.29 & 0,30 & 0.46 & 0.69 & 0,60 & 0,46 & 0,07 & 0,60 & 0.57 \\
$\mathrm{Ge}$ & 0,51 & 0.90 & 0,07 & 0.71 & 0,62 & 0.56 & 0.89 & 0,53 & 0,56 & 0,09 & 0,53 & 0.75 \\
$\mathrm{Nl}$ & 0,61 & 1.00 & 0,07 & 1.00 & 1,00 & 1.00 & 0.68 & 1,00 & 1,00 & 1,00 & 1,00 & 1.00 \\
$\mathrm{Po}$ & 0,23 & 0.99 & 0,14 & 0.16 & 0,17 & 0.34 & 0.92 & 0,18 & 0,34 & 0,33 & 0,18 & 0.57 \\
$\mathrm{Sp}$ & 0,27 & 0.84 & 0,05 & 0.17 & 0,08 & 0.11 & 0.84 & 0,26 & 0,11 & 0,07 & 0,26 & 0.47 \\
$\mathrm{Swe}$ & 0,67 & 0.53 & 0,02 & 0.05 & 0,06 & 0.09 & 0.67 & 0,05 & 0,09 & 0,09 & 0,05 & 0.37 \\
Swi & 0,50 & 0.68 & 0,03 & 0.49 & 0,49 & 0.53 & 0.82 & 0,26 & 0,53 & 0,84 & 0,26 & 0.68 \\
\hline
\end{tabular}

Notes:

* The analysis has been carried out for Canada (Cn), United States (US), Japan (Jp), Austria (Au), Finland (Fi), France (Fr), Germany (Ge), Netherlands (Nl), Portugal (Po), Spain (Sp), Sweden (Swe) and Switzerland (Swi).

** A high (low) percentage of alternative fuels results in a low (high) potential environmental pressure and therefore a low (high) index value.

*** A high value of $\mathrm{I}_{\mathrm{e}}$ goes together with a high potential environmental pressure, and a low value of $\mathrm{I}_{\mathrm{e}}$ with a low potential environmental pressure.

Most pollutant emissions by agriculture are the result of production and use of fertiliser in cattle breeding. Emissions from pesticides are mainly caused by tillage of the land. Agriculture and horticulture contribute to almost all the environmental problems. The use of fertiliser and pesticides per $\mathrm{km}^{2}$ are important indicators of potential environmental pressure. The use of fertiliser (h) is high in the Netherlands, France and Germany. Many pesticides (i) are used in the Netherlands and Japan. In addition, the numbers of pigs and cows per $\mathrm{km} 2$ ( $\mathrm{j}$ and $\mathrm{k}$ ) have been included. As expected, the Netherlands scores worst on all four indicators.

An aggregate potential environmental pressure indicator has been calculated by summing the values of all indicators relating to the sectors transport, energy, industry and agriculture, followed by a standardisation between 0.00 and 1.00 (see also Section 
1). The value 1.00 is given to the country with the highest value after summation of the sub-indicators. The aggregate indicator shows a low environmental pressure for Sweden, Canada, Spain, Finland and the United States. For densely populated countries like the Netherlands, Germany and Japan a high environmental pressure is found. This is partly due to a large number of indicators being related to area.

\section{Indicators of environmental pressure}

The environmental pressure covers the use of natural resources, soil, water and air pollution, and disturbance of the environment. These concern flow quantities like the use of resources, emissions of noxious materials, waste flows, and changes in land use. Possible indicators of environmental pressure are presented in Table 3.

Land use refers to available land area for agriculture, industry and nature. The change in the amount of agricultural area in 1993 with respect to 1970 is used as an indicator (a). This is based on the assumption that there exists a positive relationship between the amount of available agricultural area and environmental pressure caused by agriculture. In the Netherlands, Canada and France the percentage of agricultural area has increased, while in Japan, Austria and Germany it has decreased. Changes in the amount of permanent grassland seem relevant as well, but the data on these were incomplete. 
Table 3. Indicators of environmental pressure.

\begin{tabular}{|c|c|}
\hline $\begin{array}{l}\text { Environmental } \\
\text { problem }\end{array}$ & Subindicator \\
\hline Land use & $\begin{array}{l}\text { a. Change in the amount of agricultural area in } \mathrm{km}^{2} \text { (1993 in respect to } \\
\text { 1970) }\end{array}$ \\
\hline Deforestation & b. Timber use intensity* in $1000 \mathrm{~m}^{3}$ (early $90 \mathrm{~s}$ ) \\
\hline \multirow[t]{3}{*}{ Air pollution } & c. Emission of $\mathrm{SO}_{\mathrm{x}}$ per $\mathrm{km}^{2}$ (1993) \\
\hline & d. Emission of $\mathrm{NO}_{\mathrm{x}}$ per $\mathrm{km}^{2}(1993)$ \\
\hline & e. Emission of $\mathrm{CO}_{2}$ per $\mathrm{km}^{2}$ (1993) \\
\hline \multirow[t]{2}{*}{ Soil pollution } & f. Amount of produced household waste per $\mathrm{km}^{2}$ (1990/1992) \\
\hline & g. \% dumped household waste (last year available) \\
\hline \multirow[t]{2}{*}{ Water pollution } & h. Ground water abstraction per $\mathrm{km}^{2}$ (1993 of 1990) \\
\hline & i. Surface water withdrawal per $\mathrm{km}^{2}$ (1993 of 1990) \\
\hline
\end{tabular}

Note: ${ }^{*}$ Timber use intensity is the annual harvest divided by the annual increase.

A change in the amount of forested area can result from exploitation of forests for timber production. This affects the environmental pressure if the regeneration capacity is exceeded. A good indicator is the annual harvest divided by the annual increase, the so-called wood use intensity (b). Japan, Spain and the Netherlands perform well considering the wood use intensity. This means that in these countries harvesting is well adapted to the annual increase of wood in forests. In the Netherlands, however, original or old forests have largely disappeared, and planting of new trees is mainly done for production purposes. In Portugal, Switzerland and France the timber use intensity is high. This means that in these countries the annual harvest is relatively high in regard to the annual increase.

Adequate indicators of the environmental pressure caused by air pollution are the emissions of $\mathrm{SO}_{\mathrm{x}}(\mathrm{c}), \mathrm{NO}_{\mathrm{x}}(\mathrm{d})$ en $\mathrm{CO}_{2}$ (e) per area-unit. $\mathrm{SO}_{\mathrm{x}}$ and $\mathrm{NO}_{\mathrm{x}}$ are to a large extent responsible for acidification of soil and surface water, $\mathrm{CO}_{2}$ causes global warming. Although this indicator is often normalised on the number of inhabitants per country, given the comparison with the other indicators in the present study, normalisation was done on the basis of land area. The indicators of air pollution for the Netherlands and Germany show high emissions. In the United States and Sweden the emissions of air pollutants per area are relatively low. 
Indicators of the environmental pressure on soil are the amount of produced household waste (f) and the percentage of dumped waste (g). In Canada, the United States and Sweden the amount of produced household waste per area is low, while in the Netherlands, Germany and Japan it is high. The percentage of dumped waste is high in Portugal, Spain and Finland, while it is low in Switzerland, Sweden and Japan.

The amount of groundwater and surface water withdrawal per inhabitant $(\mathrm{h} / \mathrm{i})$ is an indication for the use and pressure on water. The amount of groundwater withdrawal is high in the United States and Portugal, and low in Canada, Finland and Sweden. The amount of surface water withdrawn is high in Canada, the United States, and low in Switzerland, Austria and Sweden.

A good indicator of noise pollution would be the number of people that suffer, for example, from the noise of traffic. Such an indicator is difficult to quantify since the available data are incomplete.

Table 4. Aggregation of indicators of environmental pressure in OECD-countries.

\begin{tabular}{|c|c|c|c|c|c|c|c|c|c|c|}
\hline & $\begin{array}{r}\text { Land } \\
\text { a }\end{array}$ & $\begin{array}{c}\text { Forest } \\
\qquad \mathrm{b}\end{array}$ & $\begin{array}{l}\text { Air } \\
\quad \mathrm{c}\end{array}$ & $\mathrm{d}$ & $\mathrm{e}$ & $\begin{array}{l}\text { Soil } \\
\mathrm{f}\end{array}$ & $\mathrm{g}$ & $\begin{array}{c}\text { Water } \\
\quad \mathrm{h}\end{array}$ & $\mathrm{i}$ & $\mathrm{I}_{\mathrm{d}}{ }^{* *}$ \\
\hline $\mathrm{Cn}^{*}$ & 0,97 & 0,58 & 0,03 & 0,01 & 0,01 & 0,01 & 0,87 & 0,00 & 0,02 & 0,52 \\
\hline US & 0,90 & 0,54 & 0,18 & 0,15 & 0,11 & 0,09 & 0,72 & 0,32 & 0,18 & 0,58 \\
\hline $\mathrm{Jp}$ & 0,74 & 0,29 & 0,21 & 0,27 & 0,63 & 0,66 & 0,44 & 1,00 & 1,00 & 0,76 \\
\hline $\mathrm{Au}$ & 0,81 & 0,54 & 0,08 & 0,15 & 0,16 & 0,20 & 0,78 & 0,49 & 0,05 & 0,58 \\
\hline $\mathrm{Fi}$ & 0,88 & 0,57 & 0,04 & 0,05 & 0,03 & 0,05 & 0,90 & 0,02 & 0,03 & 0,51 \\
\hline $\mathrm{Fr}$ & 0,95 & 0,64 & 0,20 & 0,19 & 0,16 & 0,24 & 0,54 & 0,32 & 0,28 & 0,63 \\
\hline $\mathrm{Ge}$ & 0,83 & 0,62 & 1,00 & 0,56 & 0,54 & 0,40 & 0,76 & 0,63 & 0,52 & 0,85 \\
\hline $\mathrm{Nl}$ & 1,00 & 0,47 & 0,40 & 1,00 & 1,00 & 1,00 & 0,55 & 0,81 & 0,88 & 1,00 \\
\hline Po & 0,93 & 1,00 & 0,28 & 0,16 & 0,11 & 0,17 & 1,00 & 0,96 & 0,22 & 0,85 \\
\hline $\mathrm{Sp}$ & 0,87 & 0,46 & 0,40 & 0,17 & 0,11 & 0,14 & 0,98 & 0,32 & 0,24 & 0,62 \\
\hline Swe & 0,89 & 0,57 & 0,02 & 0,06 & 0,03 & 0,03 & 0,51 & 0,04 & 0,03 & 0,46 \\
\hline Swi & 0,92 & 0,68 & 0,13 & 0,25 & 0,25 & 0,33 & 0,27 & 0,68 & 0,02 & 0,63 \\
\hline
\end{tabular}


In Table 4, the aggregate indicator of environmental pressure is $I_{d}$. The Table shows that environmental pressure is high in the Netherlands, Germany and Portugal, and low in Sweden, Finland and Canada.

\section{Indicators of environmental quality}

Environmental quality covers the states of natural resources, soil, water and air at a certain point in time, i.e. stock quantities. Potential indicators of environmental quality are presented in Table 5 .

The aggregate indicator of environmental quality is calculated on the basis of, among other things, the amount of agricultural land (a) and forest area (b). Countries with a relatively large amount of agricultural land are Spain, Germany and France. A high percentage of agricultural land can indicate a low environmental quality, for instance, because less space is available for nature. This appears to be true when we look at Sweden and Finland: these countries have relatively little agricultural land (a) and a relatively large area of forested land (b). The percentage of mammals that is threatened (c) is high in Austria, Germany and the Netherlands, and low in Canada, the United States and Japan. The percentage of threatened plants is high in Germany, Switzerland and Japan, and low in the United States.

Table 5. Indicators of environmental quality.

\begin{tabular}{ll}
\hline $\begin{array}{l}\text { Environmental } \\
\text { compartment }\end{array}$ & Subindicators \\
\hline Land & a. \% agricultural land (1993) \\
Forest & b. \% forested area (1993) \\
Biodiversity & c. \% threatened mammals (beginning '90) \\
& d. \% threatened flora (beginning '90) \\
Air & e. Concentration of $\mathrm{SO}_{2}$ in capital in ug/m $\mathrm{m}^{3}(1992$ or 1993) \\
& f. Concentration of $\mathrm{NO}_{2}$ in capital in ug/m $/ \mathrm{m}^{3}(1992$ or 1993) \\
\hline
\end{tabular}

The environmental quality of air, water and soil can be reflected by the concentration of polluting substances in these compartments. However, the OECD-data on concentrations of polluting materials in soil, water and air are very incomplete. Available data for the 12 
countries include the concentrations of $\mathrm{SO}_{2}$ and $\mathrm{NO}_{2}$ in the capital city of each country. The capitals of Sweden and Switzerland are characterised by relatively low, and of Spain by relatively high, concentrations of $\mathrm{SO}_{2}$ and $\mathrm{NO}_{2}$. The number and size of dumping sites could serve as indicators of waste concentration in soils. Unfortunately, also these data are incomplete for the set of countries considered.

$I_{q}$ represents the aggregate indicator of environmental quality. Table 6 shows that Sweden, Canada and Finland have a high environmental quality, while Austria, the Netherlands, Spain, France and Germany are characterised by a low environmental quality.

Table 6. Aggregation of indicators of environmental quality in OECD countries.

\begin{tabular}{|c|c|c|c|c|c|c|c|}
\hline & $\begin{array}{l}\text { Land } \\
\qquad \mathrm{A}\end{array}$ & $\begin{array}{l}\text { Forest } \\
\qquad \mathrm{b}\end{array}$ & $\begin{array}{c}\text { Biodiversity } \\
\text { c }\end{array}$ & $\mathrm{d}$ & $\begin{array}{c}\text { Air**** } \\
\text { e }\end{array}$ & $\mathrm{f}$ & $\mathrm{I}_{\mathrm{q}}^{* * * * *}$ \\
\hline $\mathrm{Cn}^{*}$ & 1,00 & 0,59 & 0,95 & 0,20 & 0,50 & 0,60 & 0,99 \\
\hline US & 0,23 & 0,41 & 0,70 & 1,00 & 0,26 & 0,40 & 0,66 \\
\hline $\mathrm{Jp}$ & 0,38 & 0,88 & 1,00 & 0,04 & 0,26 & 0,30 & 0,75 \\
\hline $\mathrm{Au}$ & 0,25 & 0,61 & 0,20 & 0,07 & 0,40 & 0,61 & 0,32 \\
\hline $\mathrm{Fi}$ & 0,53 & 1,00 & 0,62 & 0,07 & 0,74 & 0,50 & 0,91 \\
\hline $\mathrm{Fr}$ & 0,13 & 0,36 & 0,35 & 0,17 & 0,23 & 0,37 & 0,38 \\
\hline $\mathrm{Ge}$ & 0,13 & 0,39 & 0,15 & 0,02 & 0,25 & 0,68 & 0,39 \\
\hline $\mathrm{Nl}$ & 0,16 & 0,13 & 0,17 & 0,07 & 0,60 & 0,37 & 0,33 \\
\hline Po & 0,13 & 0,51 & 0,43 & 0,06 & 0,15 & 0,53 & 0,45 \\
\hline $\mathrm{Sp}$ & 0,11 & 0,42 & 0,44 & 0,08 & 0,15 & 0,29 & 0,37 \\
\hline Swe & 0,62 & 0,89 & 0,41 & 0,05 & 1,00 & 1,00 & 1,00 \\
\hline Swi & 0,38 & 0,41 & 0,28 & 0,02 & 0,67 & 0,68 & 0,59 \\
\hline
\end{tabular}

Notes:

* For a description see Table 2 .

** A high loss in biodiversity means a low environmental quality and thus a low index value.

*** A high concentration on polluting materials in the capital implies a low environmental quality and thus a low index value.

***** A high value for $\mathrm{I}_{\mathrm{q}}$ implies high environmental quality, a low value implies low quality.

\section{Indicators of environmental policy}

Measurement of environmental policy stringency can focus on the inputs (efforts) or outputs (impacts). Therefore, a distinction is made between input-oriented indicators and output- 
oriented indicators (cf. van Beers and van den Bergh 1997) ${ }^{6}$. The first type relate to the efforts made to reduce environmental pressure. Output-oriented indicators relate to the concrete results of environmental policy. Table 7 shows potential indicators of environmental policy strictness.

Table 7. Indicators of environmental policy.

\begin{tabular}{ll}
\hline Strictness of environmental policy & Sub-indicators \\
\hline Input-oriented $\left(\mathrm{I}_{\mathrm{i}}\right)$ & R\&D expenditures aimed at the environment (1991) \\
Output-oriented $\left(\mathrm{I}_{\mathrm{o}}\right)$ & a. Recycling \% of paper (last year available: 1991, \\
& 1992 or 1993) \\
& b. Recycling \% of glass (idem) \\
& c. \% change in energy-intensity 1993 in respect to \\
& 1980 \\
& d. Level of energy-intensity in Mtoe/Mtep (1980) \\
& e. Import tropical wood (1992) \\
\hline
\end{tabular}

The efforts of environmental policy are expressed by the input indicator $\mathrm{I}_{\mathrm{i}}$. A high (low) $\mathrm{I}_{\mathrm{i}}$ indicates a high (low) effort with regard to environmental policy. The level of environmental investments and $\mathrm{R} \& \mathrm{D}$ expenditures aimed at the environment can be selected as an indicator of the efforts made to reduce environmental pressure. Unfortunately, data for specific environmental investments are not available. Thus, the input indicator of environmental policy has been limited to the R\&D expenditures aimed at the environment. High R\&D expenditures occur in the Netherlands, Switzerland and Germany. Relatively low expenditures are found for Japan, the United States and France.

The output-oriented indicator 'recycling of paper and glass' ( $a$ and b) shows that densely populated countries like Switzerland and the Netherlands have developed relatively many recycling activities. In thinly populated countries like the United States and Canada clearly less recycling occurs. Possible reasons are that recycling is not profitable due to high

\footnotetext{
${ }^{6}$ Some authors consider environmental pressure or environmental quality as indicators of environmental policy (e.g., den Butter and van der Eyden 1997). In the present context this would not be useful because separate classes of indicators would end up being mixed.
} 
collecting and transport costs, and that sufficient space is available for creating sites for waste dumping.

With regard to the change in energy-intensity (c) Germany, Canada and the United States show a relatively strong decrease in energy intensity. Remarkably, the level of energy intensity (f) was high in the United States during 1980. Apparently, reducing the energy intensity has been an important issue. The same goes for Canada. In Portugal, Finland and Switzerland the energy intensity has decreased relatively less.

Finally, the import of tropical wood has been added as an indication of how a country handles globally scarce natural resources. Austria, Switzerland and Canada import relatively little tropical wood, whereas Portugal and France import relatively much of it.

$\mathrm{I}_{\mathrm{o}}$ in Table 8 presents the aggregate indicator of environmental policy. The table shows that in an international comparison Austria and Switzerland have strict environmental policy, and the United States, Finland, Portugal and France a flexible environmental policy.

Table 8. Aggregation of indicators of environmental policy in OECD-countries.

\begin{tabular}{|c|c|c|c|c|c|c|c|}
\hline & $\begin{array}{c}\text { Output } \\
\text { a }\end{array}$ & $\mathrm{b}$ & $c$ & $\mathrm{~d}$ & $\mathrm{e}$ & $\mathrm{I}_{\mathrm{o}}^{* *}$ & $\begin{array}{l}\text { Input } \\
\qquad \mathrm{I}_{\mathrm{i}}^{* *}\end{array}$ \\
\hline $\mathrm{Cn}^{*}$ & 0,41 & 0,89 & 0,80 & 0,29 & 0,83 & 0,78 & 0,39 \\
\hline US & 0,44 & 0,26 & 0,85 & 0,38 & 0,21 & 0,52 & 0,17 \\
\hline $\mathrm{Jp}$ & 0,65 & 0,67 & 0,78 & 0,68 & 0,07 & 0,69 & 0,12 \\
\hline $\mathrm{Au}$ & 1,00 & 0,90 & 0,62 & 0,61 & 1,00 & 1,00 & 0,44 \\
\hline $\mathrm{Fi}$ & 0,58 & 0,60 & 0,36 & 0,36 & 0,43 & 0,56 & 0,46 \\
\hline $\mathrm{Fr}$ & 0,54 & 0,57 & 0,72 & 0,64 & 0,05 & 0,61 & 0,17 \\
\hline $\mathrm{Ge}$ & 0,59 & 0,89 & 1,00 & 0,45 & 0,14 & 0,74 & 0,88 \\
\hline $\mathrm{Nl}$ & 0,68 & 0,92 & 0,72 & 0,43 & 0,07 & 0,68 & 1,00 \\
\hline Po & 0,53 & 0,38 & 0,00 & 1,00 & 0,03 & 0,47 & 0,73 \\
\hline $\mathrm{Sp}$ & 1,00 & 0,37 & 0,55 & 0,80 & 0,07 & 0,68 & 0,88 \\
\hline Swe & 0,64 & 0,67 & 0,72 & 0,38 & 0,73 & 0,76 & 0,76 \\
\hline Swi & 0,69 & 1,00 & 0,46 & 0,78 & 0,86 & 0,92 & 0,98 \\
\hline
\end{tabular}




\section{Relationships between the aggregate indicators}

Table 9 summarizes the aggregate indicators of economic activities (potential environmental pressure), (actual) environmental pressure, environmental quality, and environmental policy that have been discussed and calculated in the previous sections. Two macro-economic indicators have been added to these, namely the GNP per capita and the unemployment percentage. In addition, the population density $(\mathrm{P})$ is listed. The reason for including these three macro-level indicators is that the potential correlation with the environmental-economic indicators can be studied. For instance, the question can be raised whether a complicated process of aggregation can be omitted and replaced by selecting a straightforward indicator (population density) or aggregate indicators that are already being calculated on a regular basis by national or international statistical offices (GNP and unemployment).

Table 9. An overview of aggregate environmental-economic indicators.

\begin{tabular}{|c|c|c|c|c|c|c|c|c|}
\hline & GNP/cap. & $\mathrm{P}$ & $\mathrm{U} \%$ & $\mathrm{I}_{\mathrm{e}}$ & $\mathrm{I}_{\mathrm{d}}$ & $\mathrm{I}_{\mathrm{q}}$ & $\mathrm{I}_{\mathrm{i}}$ & $\mathrm{I}_{\mathrm{o}}$ \\
\hline $\mathrm{Cn}$ & 18695,1 & 2,9 & 0,112 & 0,39 & 0,52 & 0,99 & 0,39 & 0,78 \\
\hline US & 23417,9 & 26,3 & 0,069 & 0,48 & 0,58 & 0,66 & 0,17 & 0,52 \\
\hline $\mathrm{Jp}$ & 19006,5 & 330,0 & 0,025 & 0,82 & 0,76 & 0,75 & 0,12 & 0,69 \\
\hline $\mathrm{Au}$ & 17287,3 & 95,2 & 0,043 & 0,60 & 0,58 & 0,32 & 0,44 & 1,00 \\
\hline $\mathrm{Fi}$ & 14574,1 & 15,0 & 0,177 & 0,51 & 0,51 & 0,91 & 0,46 & 0,56 \\
\hline Fr & 17976,7 & 104,6 & 0,116 & 0,57 & 0,63 & 0,38 & 0,17 & 0,61 \\
\hline $\mathrm{Ge}$ & 16922,6 & 227,5 & 0,104 & 0,75 & 0,85 & 0,39 & 0,88 & 0,74 \\
\hline $\mathrm{Nl}$ & 16435,3 & 410,2 & 0,062 & 1,00 & 1,00 & 0,33 & 1,00 & 0,68 \\
\hline Po & 10366,9 & 107,5 & 0,055 & 0,57 & 0,85 & 0,45 & 0,73 & 0,47 \\
\hline $\mathrm{Sp}$ & 12635,1 & 77,4 & 0,227 & 0,47 & 0,62 & 0,37 & 0,88 & 0,68 \\
\hline Swe & 15978,0 & 19,4 & 0,082 & 0,37 & 0,46 & 1,00 & 0,76 & 0,76 \\
\hline Swi & 21075,8 & 168,0 & 0,037 & 0,68 & 0,63 & 0,59 & 0,98 & 0,92 \\
\hline \multicolumn{9}{|c|}{ Notes: } \\
\hline \multicolumn{9}{|c|}{ GNP/cap. = Gross National Product per inhabitant in US\$ in constant prices, 1993.} \\
\hline \multicolumn{9}{|c|}{$\mathrm{P}=$ Population density, number of people per $\mathrm{km}^{2}, 1993}$. \\
\hline \multicolumn{9}{|c|}{ U\% = Unemployment percentage, 1993 (Labour force sample surveys). } \\
\hline \multicolumn{9}{|c|}{$\mathrm{I}_{\mathrm{e}}=$ Aggregate index of the influence of economic activities on environmental pressure (potential environmental pressure). } \\
\hline \multicolumn{9}{|c|}{$\mathrm{I}_{\mathrm{d}}=$ Aggregate index of (actual) environmental pressure. } \\
\hline \multicolumn{9}{|c|}{$I_{q}=$ Aggregate index of environmental quality. } \\
\hline \multicolumn{9}{|c|}{$\mathrm{I}_{\mathrm{i}}=$ Aggregate index of I environmental policy (input). } \\
\hline \multicolumn{9}{|c|}{$\mathrm{I}_{\mathrm{o}}=$ Aggregate index of environmental policy (output). } \\
\hline
\end{tabular}


It is striking that the Netherlands score worst on the indicator of economic activity (potential environmental pressure, $\mathrm{I}_{\mathrm{e}}$ ), environmental pressure and environmental quality, and scores best on the indicator of strictness of environmental policy $\left(\mathrm{I}_{\mathrm{i}}\right)$. One explanation is that the first three indicators relate to population density. Thinly populated countries like Canada and Sweden are therefore characterised by low scores on the indicators of potential and actual environmental pressure and a high environmental quality. Looking at the policy indicators, the European countries in general are quite progressive in terms of indicator $\mathrm{I}_{\mathrm{i}}$. Note that on this indicator France scores bad, and Portugal and Spain score good.

The relation between the aggregate indicators presented in Table 9 can be studied more carefully by means of a statistical analysis. In view of a limited number of countries in the sample, the analysis is based on calculating correlation coefficients. Table 10 presents the results of this. ${ }^{7}$ The most remarkable findings can be summarised as follows.

A strong coherence exists between the potential environmental pressure (economic activities, $\mathrm{I}_{\mathrm{e}}$ ) and the actual environmental pressure $\left(\mathrm{I}_{\mathrm{d}}\right)$. This result is not unexpected given the causal chain in Figure 1. A negative correlation exists between the actual environmental pressure and the environmental quality, which means that a higher environmental pressure goes along with a lower environmental quality. Moreover, a high population density (P) correlates very strongly with a high potential environmental pressure $\left(\mathrm{I}_{\mathrm{e}}\right)$ and a high environmental pressure $\left(\mathrm{I}_{\mathrm{d}}\right)$, and negatively with a low environmental quality $\left(\mathrm{I}_{\mathrm{q}}\right)$. The results are a consequence of the fact that densely populated countries often have energy intensive production, high mobility rates and intensive agricultural activities. Also the reverse causality can play a role, i.e. intensifying the activities, both in spatial as well as in environmental respect, makes a high population density possible. The negative relation between potential environmental pressure $\left(\mathrm{I}_{\mathrm{e}}\right)$ and environmental quality $\left(\mathrm{I}_{\mathrm{q}}\right)$ means that a higher potential environmental pressure results in a lower environmental quality. This suggests a certain persistence or trend with regard to environmental pressure, quality and policy. The input indicator of environmental policy $\left(\mathrm{I}_{\mathrm{i}}\right)$ shows little correlation with environmental quality, which can be explained by two opposite effects: (i) a higher (lower) environmental quality stimulates a relatively flexible (strict) environmental policy, as observed for thinly (densely)

\footnotetext{
${ }^{7}$ Statistical regression with several variables offered little extra information.
} 
populated countries like Canada and Finland (the Netherlands, Germany and Spain); and (ii) a strict (flexible) environmental policy has a positive (negative) impact on environmental quality, as shown by Sweden (France, Austria and the United States). The output indicator of environmental policy $\left(I_{0}\right)$ shows a weak negative correlation with environmental pressure and no correlation with potential environmental pressure $\left(\mathrm{I}_{\mathrm{e}}\right)$. This could indicate policy action with 'marginal measures' (aimed at 'end-of-pipe' or 'abatement' technology) without affecting the volume of activities that cause environmental pressure. This is evident in many countries where mobility and material consumption increase steadily in spite of environmental regulations.

Table 10. Correlation coefficients.

\begin{tabular}{lrrrrrrrr}
\hline & GNP/cap. & \multicolumn{1}{l}{$\mathrm{P}$} & $\mathrm{U} \%$ & $\mathrm{I}_{\mathrm{e}}$ & $\mathrm{I}_{\mathrm{d}}$ & $\mathrm{I}_{\mathrm{q}}$ & $\mathrm{I}_{\mathrm{i}}$ & $\mathrm{I}_{\mathrm{o}}$ \\
\hline GNP/cap. & 1,000 & & & & & & & \\
$\mathrm{P}$ & 0,049 & 1,000 & & & & & & \\
$\mathrm{U} \%$ & $-0,426$ & $-0,428$ & 1,000 & & & & & \\
$\mathrm{I}_{\mathrm{e}}$ & 0,083 & 0,970 & $-0,438$ & 1,000 & & & & \\
$\mathrm{I}_{\mathrm{d}}$ & -0.229 & 0,848 & -0.315 & 0.849 & 1,000 & & & \\
$\mathrm{I}_{\mathrm{q}}$ & 0,200 & $-0,456$ & 0,045 & $-0,518$ & -0.619 & 1,000 & & \\
$\mathrm{I}_{\mathrm{I}}$ & $-0,404$ & 0,269 & 0,117 & 0,256 & 0,376 & $-0,291$ & 1,000 & \\
$\mathrm{I}_{\mathrm{o}}$ & 0,292 & 0,093 & $-0,276$ & 0,093 & $-0,211$ & $-0,069$ & 0,244 & 1,000 \\
\hline
\end{tabular}

The relation between GNP per inhabitant (GNP/cap.) and unemployment percentage (U\%) on the one hand, and the different aggregate environmental indicators on the other hand, is as follows. GNP/cap. shows a weak negative relation with aggregate environmental pressure. An explanation for this relationship offered in the discussion on the environmental (green) Kuznets curve (e.g., de Bruyn and Heintz 1999) is that when incomes rise the environment becomes a luxury good. Next, a (weak) negative relation exists between unemployment and the potential environmental pressure (economic activities). An explanation could be that a trade-off is made between less pollution and less unemployment.

Finally, the relation between the input and output indicators of environmental policy stringency is very weak. This could mean that at least one of the indicators is not chosen or 
aggregated very well. Alternatively, this result could signal that either environmental policy is not very effective in various countries in the sample (not in all, because then correlation would be more significant), or that policies are changing in certain countries. After all, a delay exists between the implementation (input) and the results (output) of environmental policy. In our view, an output indicator, perhaps expanded with more sub-indicators, can give a better idea of the relative strictness or flexibility of environmental policy in one country relative to other countries. This is supported by the correlation analysis, which suggests that GNP/cap. is negatively related to the input indicator of strictness of environmental policy, and weakly positively related to the output indicator.

\section{Conclusions}

In this article, four types of aggregate indicators have been composed, for: economic activities (potential environmental pressure), (actual) environmental pressure, environmental quality, and environmental policy. These indicators have been calculated for, and compared among, 12 OECD countries. These indicators can play a useful role in the evaluation of environmental policy and internationally comparable macro-analysis.

Empirical regularities between the computed aggregate indicators have been examined. These suggest clear relationships between indicators of economic activity (potential environmental pressure), environmental pressure and environmental quality. This finding can be largely explained by the normalization of the indicators on the basis of population density, which is supported by the strong correlation between population density and the potential and actual environmental pressure ${ }^{8}$. Relationships between indicators of environmental policy and the other indicators are very weak. Various explanations can be given. Practical reasons are insufficient data quality, subjective subindicators, and aggregation with equal weights. Substantive explanations relate to the fact that causality runs in opposite directions (see Figure 1): (lack of) environmental pressure and quality stimulate environmental regulations; and environmental policy has an impact on potential and actual environmental pressure, and a delayed impact on

\footnotetext{
${ }^{8}$ Normalising the indicators on population size produced less clear correlation between the aggregate indicators. Adding or omitting an indicator did not have a significant impact on the aggregate indicators.
} 
environmental quality. Static comparisons of indicators cannot capture all of these effects.

The analysis may be improved upon in many respects. In order to accomplish this more complete data among countries should become available. This would allow for construction of better aggregate indicators. In addition, times series data on indicators could be useful to test for delays in relationships between indicators. Finally, combining the resulting panel data with economic theories and models could lead to a better understanding of the various aggregate relationships among economic, environmental and policy indicators.

\section{References}

Adriaanse, A., 1993. Environmental Policy Performance Indicators. Sdu Publishers, Den Haag.

Beers, C. van, and J.C.J.M. van den Bergh, 1997. 'An empirical multi-country analysis of the impact of environmental regulation on foreign trade flows'. Kyklos 50: 29-46.

Bergh, J.C.J.M. van den, and H. Verbruggen, 1999. 'Spatial sustainability, trade and indicators: an evaluation of the 'ecological footprint' ', Ecological Economics 29: 63-74.

Bruyn, S.M. de, and J.B. Opschoor. 1997. 'Developments in the throughput-income relationship: theoretical and empirical observations'. Ecological Economics. 20(3): 255-268.

Bruyn, S.M. de, and R.J. Heintz, 1999. The environmental Kuznets curve hypothesis. In: J.C.J.M. van den Bergh (ed.). Handbook of Environmental and Resource Economics. Edward Elgar, Cheltenham.

Butter, F.A.G. den, 1992. 'The mirror of cleanliness: on the construction and use of an environmental index'. In: J.J. Krabbe en W.J.M. Heijman (red.). National Income and Nature: Externalities, Growth and Steady state: 49-75. Kluwer Academic Publishers, Dordrecht.

Butter, F.A.G. den, en J.A.C. van der Eyden, 1998, A pilot index for environmental policy in The Netherlands, Energy Policy 26: 95-101.

Huppes, G., H. Sas, E. de Haan and J. Kuyper, 1997. 'Efficiënte milieuinvesteringen' ('Efficient environmental investments'). Milieu - Dutch Journal of Environmental Science 12(3): 126-133 (in Dutch).

Goff, B., 1996. Regulation and Macroeconomic Performance. Kluwer Academic Publishers, Boston.

Hope, C., J. Parker and S. Peake. 1992. 'A pilot environmental index for the UK in the 1980s'. Energy Policy 20: 335-343.

Jänicke, M., H. Monch, T. Ranneberg and U.E. Simonis, 1989. 'Economic structure and environmental impacts: East-West comparisons'. The Environmentalist 9: 171182. 
Kuik, O., and H. Verbruggen (eds.), 1991. In Search of Indicators of Sustainable Development. Kluwer Academic Publishers, Dordrecht.

Laan, R. van der, and A. Nentjes, 1992. 'Het Nederlandse milieu in Europees perspectief' ('The Netherlands' environment in a European context'). EconomischStatistische Berichten. 77: 621-625 (in Dutch).

Milon, J.W., and J.F. Shogren, 1995 (red.). Integrating Economic and Ecological Indicators: Practical Methods for Environmental Policy Analysis. Praeger, Westport, Connecticut.

OECD, 1985b. OECD Environmental Data - Compendium 1985. Organisation for Economic Cooperation and Development, Paris.

OECD, 1993. OECD Environmental Data - Compendium 1993. Organisation for Economic Cooperation and Development, Paris.

OECD, 1994. Environmental Indicators. Organisation for Economic Cooperation and Development, Paris.

OECD, 1995. Environmental Data - Compendium 1995. Organisation for Economic Cooperation and Development, Paris.

RIVM, 1995. Achtergronden bij: Milieubalans '95 ('Background Document to State of the Environment for the Netherlands)'. Samsom H.D. Tjeenk Willink, Alphen aan den Rijn (in Dutch).

Stanners, D., and P. Bourdeau (red.), 1995. Europe's Environment: The Dobris Assessment. European Environment Agency, Copenhagen. 